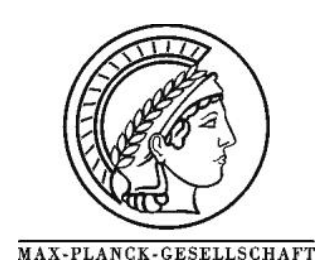

\title{
In situ Surface Characterization of the Intermetallic Compound PdGa- A Highly Selective Hydrogenation Catalyst
}

\author{
K. Kovnir, ${ }^{1,2^{*}}$ M. Armbrüster, ${ }^{2, \#}$ D. Teschner, ${ }^{2}$ T. Venkov, ${ }^{2}$ L. Szentmiklósi, ${ }^{3}$ \\ F.C. Jentoft, ${ }^{2}$ A. Knop-Gericke, ${ }^{2}$ Yu. Grin, ${ }^{1}$ R. Schlögl ${ }^{2}$ \\ ${ }^{1}$ Max-Planck-Institut für Chemische Physik fester Stoffe, Nöthnitzer Str. 40, 01187 Dresden, Germany \\ ${ }^{2}$ Department of Inorganic Chemistry, Fritz-Haber-Institute of the Max-Planck-Society, Faradayweg 4-6, \\ 14195 Berlin, Germany \\ ${ }^{3}$ Institute of Isotopes, Hungarian Academy of Sciences, Post Office Box 77, Budapest H-1525, \\ Hungary \\ " Corresponding author: e-mail kovnir@fhi-berlin.mpg.de, Fax: +49 3514646 4002, Tel.: +49 35146464253 \\ \# Current address: University of Cambridge, Chemistry Department, Lensfield Road, Cambridge CB2 1EW, \\ United Kingdom
}

Available online 14 January 2009.

Dedicated to Prof. Dr. Gerhard Ertl

\begin{abstract}
The structurally well-defined intermetallic compound PdGa - a highly selective catalyst for the semi-hydrogenation of acetylene - was characterized by Fourier transform infrared spectroscopy (FTIR), in situ X-ray photoelectron spectroscopy (XPS) and in situ Prompt Gamma Activation Analysis (PGAA). A strong modification of the electronic states in PdGa compared to elemental Pd was revealed as well as the complete isolation of the Pd atoms on the surface of PdGa. In situ investigations proved the high stability of the surface, thus excluding segregation phenomena (common for alloys) or sub-surface chemistry involving $\mathrm{C}$ and/or $\mathrm{H}$ atoms (known for elemental $\mathrm{Pd}$ ). By suppressing the sub-surface chemistry, the electronic modification as well as the site isolation lead to the high selectivity and long-term stability of PdGa in the semi-hydrogenation of acetylene.
\end{abstract}

Keywords: PdGa; Intermetallic compound; In-situ characterization; X-ray photoelectron spectroscopy; Fourier transform infrared spectroscopy; Prompt gamma activation analysis; Acetylene hydrogenation; Site isolation.

\section{Introduction}

Selective hydrogenation of alkynes is an industrially relevant and scientifically interesting reaction. For example, the semi-hydrogenation of acetylene $\left(\mathrm{C}_{2} \mathrm{H}_{2}+\mathrm{H}_{2} \rightarrow\right.$ $\mathrm{C}_{2} \mathrm{H}_{4}, \Delta \mathrm{H}=-172 \mathrm{~kJ} / \mathrm{mol}$ ) is used to remove traces of acetylene from the ethylene feed to produce polyethylene (annually $>5 * 10^{7} \mathrm{t}$ ) [1]. Typical hydrogenation catalysts consist of palladium dispersed on metal oxides. Palladium metal exhibits high activity but limited selectivity. Moreover, Pd catalysts deactivate [2] under hydrogenation conditions by the formation of carbonaceous deposits resulting from polycondensation of unsaturated compounds. According to numerous surface studies [3], the presence of extended Pd sites on the catalyst surface is one of the main reasons for unselective operation. Indeed, hydrogenation of acetylene to ethylene and, consequently, to ethane requires a minimum of Pd atoms for its active site. In turn, deactivation pathways to carbon deposits via oligomerisation and formation of ethylidine require spacious active sites. The high hydrogenation activity of Pd towards ethane is attributed to the formation of $\beta$-palladium hydride and consequently, active sub-surface hydrogen [4]. The suppression of subsurface hydrogen formation is crucial for the selective hydrogenation of acetylene. 
The successful catalyst requires a modification of its structure preventing the sub-surface chemistry without elimination of the atomic hydrogen surface species. Alloying Pd with $\mathrm{Ag}$ is the current practical solution for acetylene hydrogenation [5]. However, random distribution of different atoms on the crystallographic sites, little electron localization between Pd and the other metal and segregation phenomena present in alloys [5] leave room for further improvement.

Recently we introduced a novel concept for the rational development of the alkynes hydrogenation catalysts [6]. Exploring of the Pd-Ga intermetallic compounds allows to overcome main drawbacks of conventional catalysts. In utilized intermetallic compounds, $\mathrm{Pd}$ atoms separated from each other and their atomic environment is fixed by the realized crystal structure which should result in single Pd sites on the surface in high abundance. In turn, covalent (directed) interaction between Pd and Ga provides in-situ stability of the crystal structure as well as polarization of the Pd atoms to maximize the activation barrier for hydrogen atoms to enter into the bulk, thus preventing subsurface hydrogen formation and enhancing the selectivity. The concept of using intermetallic compounds with covalent bonding rather than alloys is a suitable way to arrive at long-term stable catalyst with pre-selected electronic and local structural properties. Detailed in situ investigations of bulk structure of $\mathrm{PdGa}$ and $\mathrm{Pd}_{3} \mathrm{Ga}_{7}$ by DSC/TG, XRD and EXAFS during thermal treatment under various inert or reactive gas atmospheres showed that the long- and shortrange ordered crystal structures of the materials are intact up to $600 \mathrm{~K}$. Both intermetallic compounds exhibit a higher selectivity and enhanced long-term stability in acetylene hydrogenation than commercial supported $\mathrm{Pd} / \mathrm{Al}_{2} \mathrm{O}_{3}$ and an unsupported Pd-Ag alloy [6-8]. While the former studies explored the catalytic properties and the bulk stability of the compounds, we present here a careful characterization (including in situ) of the surface of PdGa and compare it with the bulk structure. The correlations between the surface structure and the catalytic properties are also discussed.

\section{Experimental}

\subsection{Preparation}

Details of the preparation can be found elsewhere [68]. Briefly, PdGa was prepared by melting the appropriate amounts of Pd (ChemPur $99.95 \%$ ) and Ga (ChemPur $99.99 \%$ ) under protective Ar atmosphere in a high frequency furnace and subsequent annealing of the obtained ingot in an evacuated quartz glass ampoule at $1073 \mathrm{~K}$ for $170 \mathrm{~h}$. The phase purity was controlled by X-ray powder diffraction (Guinier camera, Huber G670, image plate, $\mathrm{CuK} \alpha_{1}$ with $\lambda=1.540562 \AA$ ). For further investigations the material was powdered inside a glove box (Ar atmosphere, $\mathrm{O}_{2}$ and $\mathrm{H}_{2} \mathrm{O}$ below $1 \mathrm{ppm}$ ) to avoid significant contamination of the surface.

\subsection{X-ray photoelectron spectroscopy (XPS)}

High-pressure X-ray photoelectron spectroscopy experiments were performed at beamline U49/2-PGM1 at BESSY (Berlin, Germany). Details of the setup have been published earlier [9]. The photoelectron spectrometer system uses a differentially pumped lens system between the sample cell and the electron analyzer, allowing XPS investigations during catalytic conditions in the mbar pressure range. Dense pills of PdGa $(8 \mathrm{~mm}$ in diameter, $0.7 \mathrm{~mm}$ thick) were either produced by pressing $\mathrm{PdGa}$ powder at room temperature in a stainless steel pressing tool (as-cast sample) or by spark plasma sintering (SPS) [10] at $873 \mathrm{~K}$ and $400 \mathrm{MPa}$ in a tungsten carbide pressing tool. Samples were prepared in argon atmosphere inside a glove box. The as-cast PdGa pill and one of SPS-pressed pills (SPS-air sample) were exposed to air prior to the measurements, whereas a second SPS-pressed pill (SPS sample) was introduced to the XPS setup avoiding air contact by using a transfer chamber. Both SPS-pressed pills were $\mathrm{Ar}^{+}$sputtered prior to the measurements.

XPS investigations were performed in UHV $\left(10^{-8}\right.$ mbar) and under reaction conditions $\left(1.0 \mathrm{mbar}\right.$ of $\mathrm{H}_{2}$ (Westfalen Gas, 99.999\%) and 0.1 mbar of $\mathrm{C}_{2} \mathrm{H}_{2}$ (solvent free, Linde, $99.6 \%$ ) at $400 \mathrm{~K}$ ). An in situ experiment included introduction of the gases at room temperature, equilibration for 15 minutes, heating the sample to the corresponding temperature with a rate of $10 \mathrm{~K} / \mathrm{min}$ and equilibration for another 15 minutes after which the XP spectra were recorded. Gas-phase analysis was carried out using a quadrupole Balzers mass spectrometer connected by a leak valve to the experimental cell. Ion currents corresponding to acetylene $(m / e=26)$, ethylene $(m / e=27)$ and ethane $(m / e=$ 30) were monitored.

To keep the information depth of the XP spectra alike, $\mathrm{Pd} 3 d, \mathrm{Ga} 3 p, \mathrm{Ga} 3 d$ and $\mathrm{C} 1 s$ spectra were recorded with varying wavelength of the incoming radiation, resulting in photoelectrons with similar kinetic energies. Three different kinetic energies were chosen $-780 \mathrm{eV}, 380 \mathrm{eV}$ and $150 \mathrm{eV}$ - which correspond to information depths (3times the inelastic mean free path) of $\sim 4 \mathrm{~nm}, 2.5 \mathrm{~nm}$ and $1.5 \mathrm{~nm}$, respectively, for the clean PdGa [11]. Surface concentrations of the elements were determined from the $\operatorname{Pd} 3 d$, $\mathrm{Ga} 3 p$ and $\mathrm{C} 1 s$ peak areas.

\subsection{Fourier transform infrared spectroscopy (FTIR)}

Fourier transform infrared spectroscopic measurements were carried out using a Perkin-Elmer S 2000 spectrometer in transmission mode with a resolution of $4 \mathrm{~cm}^{-1}$. PdGa powder was mixed with high surface area silica (Degussa) in a 1:10 weight ratio and subsequently pressed into thin wafers. Commercial $\mathrm{Pd} / \mathrm{Al}_{2} \mathrm{O}_{3}$ (Sigma-Aldrich 205710, 5 wt.-\% Pd, BET surface: $114 \mathrm{~m}^{2} / \mathrm{g}$, Pd active surface area $5.6 \mathrm{~m}^{2} / \mathrm{g}$ [7]) was used as self-supporting wafers. Prior to the measurements the samples of were treated in situ in a 
heatable section of the IR cell at $673 \mathrm{~K}$ for one hour in either 500 mbar of hydrogen $(\mathrm{PdGa})$ or vacuum $\left(\mathrm{Pd} / \mathrm{Al}_{2} \mathrm{O}_{3}\right)$. Subsequently, the samples were cooled down to the designated temperature and FTIR spectra were collected. For each spectrum 32 scans were accumulated. To exclude any influence of $\mathrm{SiO}_{2}$, blank measurements were performed and no bands in the region of $2100-1800 \mathrm{~cm}^{-1}$ were observed. Presented are difference spectra obtained by subtraction of the spectrum of the activated sample in vacuum from the spectrum in presence of the probe molecule - carbon monoxide (Messer-Griesheim, 99.997\%).

\subsection{Prompt Gamma Activation Analysis (PGAA)}

In situ Prompt Gamma Activation Analysis (PGAA) was performed at the cold neutron beam of the Budapest Neutron Centre, Budapest, Hungary [12a]. $\mathrm{An}_{2} \mathrm{Al}_{2} \mathrm{O}_{3}$ tube reactor (inner diameter of $2 \mathrm{~mm}$ ) loaded with $200 \mathrm{mg}$ of ascast PdGa powder was placed into the neutron beam. The total hydrogen uptake of PdGa was studied in pure hydrogen and in a hydrogen/acetylene mixture $\left(\mathrm{C}_{2} \mathrm{H}_{2}: 4 \mathrm{~mL} / \mathrm{min}\right.$; $\mathrm{H}_{2}: 40 \mathrm{~mL} / \mathrm{min}$ ) at near room temperature and ambient pressure. Prompt gamma rays were collected by a Compton-suppressed high-purity germanium detector. The molar $\mathrm{H} / \mathrm{Pd}$ ratio, i.e. the amount of hydrogen dissolved in PdGa and adsorbed on its surface, was determined from the characteristic peak areas corrected by the detector efficiency and the nuclear data of the elements [12b]. Since the hydrogen spectrum contains extra contributions from gas phase hydrogen in the feed and moisture in the "viewing angle" of the detector, blank experiments were performed without $\mathrm{PdGa}$ in the reactor but otherwise identical conditions to subtract the extra amount of hydrogen. Experiments were also carried out with elemental $\mathrm{Pd}$ for comparison [13].

\subsection{Scanning electron microscopy (SEM) and chemical analysis}

Scanning electron microscopy was performed with a Hitachi S4800 equipped with a cold FEG (Field Emission Gun) and a Philips XL30 operating with a $\mathrm{LaB}_{6}$ cathode. Samples were mounted on Al-holders with conducting carbon tape.

The silica (Degussa) used for preparing the FTIR wafers was chemically analysed by inductively coupled plasma - optical emission spectrometry (ICP-OES) with a Varian Vista RL spectrometer. All values are the average of at least three replicates.

\subsection{Catalysis}

Details of the catalytic measurements are published elsewhere [6-8]. Measurements were carried out in a plugflow reactor $(30 \mathrm{~mL} / \mathrm{min})$ with a high excess of ethylene
(0.5\% acetylene, $5 \%$ hydrogen $(99.999 \%)$ and $50 \%$ ethylene $(99.95 \%)$ in helium $(99.999 \%))$. To introduce the small amount of acetylene, pre-mixed 5\% acetylene (solvent free, 99.6\%) in helium (99.996) was used. All gases were supplied by Westfalen Gas (Germany). The concentrations of the educts and products were monitored by a micro gas chromatograph (Varian CP 4900).

\section{Results and Discussion}

\subsection{Catalysis}

PdGa revealed high selectivity and long-term stability in the semi-hydrogenation of acetylene. Catalytic properties of as-cast [6], milled [6-7] and chemically etched [8] PdGa were reported by us recently. Catalytically active samples derived from as-cast PdGa powder were used in the XPS and PGAA measurements. Here, the catalytic activity of the mechanical mixture of PdGa with silica used for the FTIR measurements was tested to prove that the catalytic properties of $\mathrm{PdGa}$ were preserved. Chemical analysis of the silica showed the absence of any transition metals above the detection limit $(0.06$ wt.- $\%)$ and a blank catalytic test did not reveal any activity. The results of the catalytic tests for the physical mixture of PdGa and silica are shown in Figure 1 in comparison with as-cast and milled PdGa. In contrast to the latter two samples, the

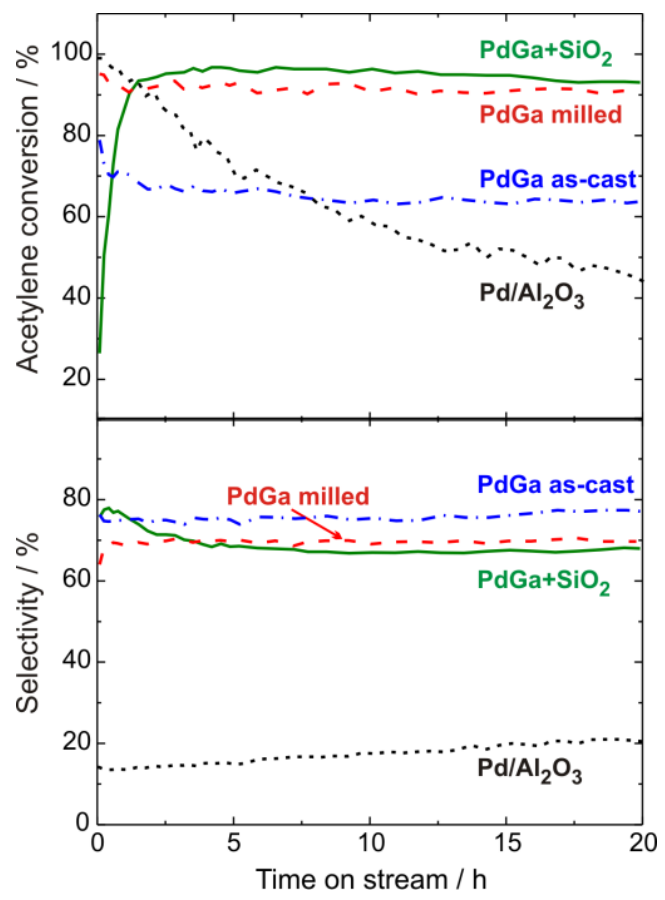

Fig. 1: Acetylene conversion (top) and selectivity (bottom) for ascast $(400 \mathrm{mg})$, milled $(20 \mathrm{mg})$ and ground with silica $(8.5 \mathrm{mg})$ samples of $\mathrm{PdGa}$. For comparison the data of a commercial $5 \mathrm{wt}$.$\% \mathrm{Pd} / \mathrm{Al}_{2} \mathrm{O}_{3}(0.15 \mathrm{mg})$ is also shown. Feed composition: $0.5 \%$ $\mathrm{C}_{2} \mathrm{H}_{2}+5 \% \mathrm{H}_{2}+50 \% \mathrm{C}_{2} \mathrm{H}_{4}+44.5 \% \mathrm{He}$; total flow $30 \mathrm{~mL} / \mathrm{min}$; isothermal experiment at $473 \mathrm{~K}$. 
Table 1: Acetylene conversion, selectivity and activity of as-cast, milled and mixed with silica PdGa after 20 hours time on stream.

\begin{tabular}{lcccc}
\hline Sample & $\begin{array}{c}\text { Sample } \\
\text { mass } / \mathrm{mg}\end{array}$ & $\begin{array}{c}\text { Acetylene } \\
\text { conversion } / \%\end{array}$ & $\begin{array}{c}\text { Selectivity } \\
/ \%\end{array}$ & $\begin{array}{c}\text { Activity / } \\
g_{\mathrm{C}_{2} \mathrm{H}_{2}} /\left(\mathrm{g}_{\text {cat }} \cdot \mathrm{h}\right)\end{array}$ \\
\hline PdGa as-cast & 400 & 64 & 77 & 0.02 \\
PdGa milled & 20 & 91 & 70 & 0.43 \\
${\mathrm{PdGa}+\mathrm{SiO}_{2}}$ & 8.5 & 93 & 68 & 1.04 \\
\hline
\end{tabular}

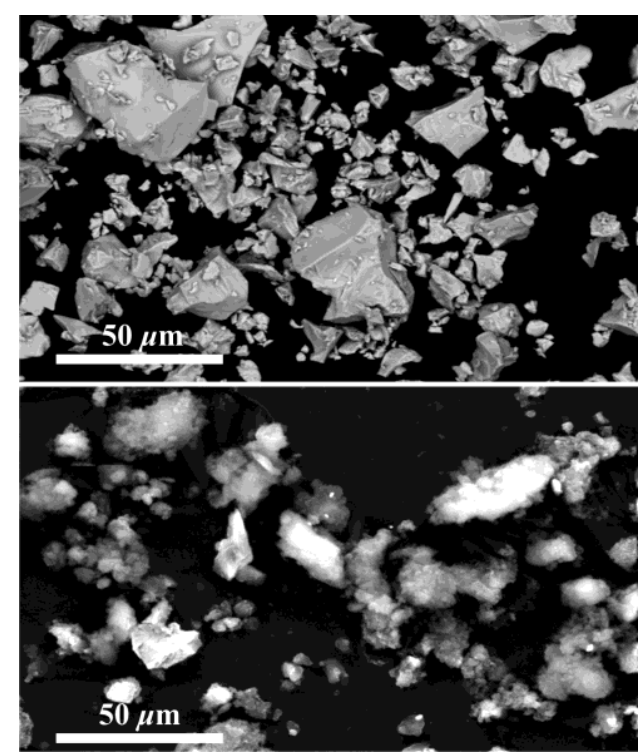

Fig. 2: SEM images of as-cast $\mathrm{PdGa}$ (top) and $\mathrm{PdGa}$ after grinding with silica (bottom). Grinding $\mathrm{PdGa}$ with $\mathrm{SiO}_{2}$ results in much smaller particles as well as in coverage of the particles with silica.

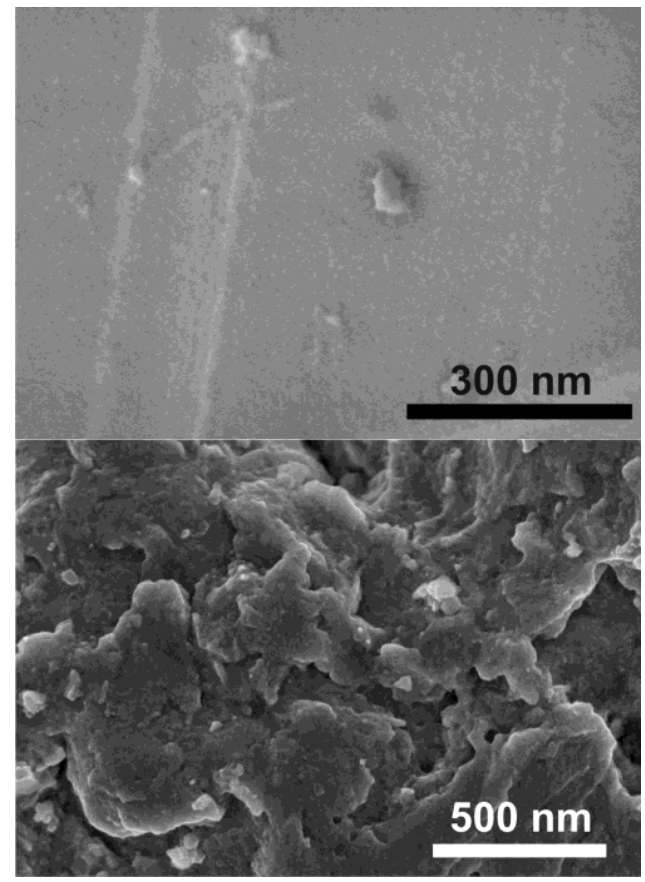

Fig. 3: High resolution SEM images of as-cast (top) and milled (bottom) PdGa. While the as-cast PdGa reveals a very smooth surface, the surface after milling is rough - resulting in structural disorder.
$\mathrm{PdGa}+\mathrm{SiO}_{2}$ sample showed a strong activation during the first hour. Consequently, the $\mathrm{PdGa}+\mathrm{SiO}_{2}$ wafers were reduced in situ in the IR cell in 500 mbar of hydrogen at 673 $\mathrm{K}$ for one hour prior to the FTIR measurements.

Comparison of differently treated $\mathrm{PdGa}$ samples (Figure 1) revealed similar selectivity and long-term stability, while PdGa samples that were milled or ground with silica exhibited significantly higher activity (Table 1 ). This is reasonable because milling is increasing the surface area [7-8]. Hence, grinding with silica is expected to have a similar effect. Indeed, SEM investigations revealed that grinding with silica diminishes the largest $\mathrm{PdGa}$ particles and decreases the average particle size (Figure 2). Mechanical treatment, like grinding or milling introduces imperfections on the surface (Figure 3), thus partly disturbing the site isolation, which is expressed in a slightly lower selectivity as compared with as-cast PdGa.

\subsection{PGAA}

The absence of hydride formation is crucial to obtain high selectivity in the semi-hydrogenation of acetylene. Recently some of us have demonstrated that the amount of hydrogen dissolved in palladium can be quantified, even under reaction conditions, i.e. in situ [13]. The technique, Prompt Gamma Activation Analysis, makes use of the radiative neutron capture process in which the nuclei of a chemical element, after absorbing a neutron, emit characteristic prompt gamma rays during the de-excitation process. Since PGAA is sensitive to hydrogen due to its high neutron capture cross section, hydrogen atoms dissolved in solids can be quantified. Figure 4 illustrates the hydrogen uptake of PdGa in comparison with pure Pd. The atomic $\mathrm{H} / \mathrm{Pd}$ ratio is 0.01 in hydrogen atmosphere at room temperature and 0.012 in the $\mathrm{H}_{2} / \mathrm{C}_{2} \mathrm{H}_{2}$ feed at $323 \mathrm{~K}$. Since the error bar at this low hydrogen concentration is high (35$45 \%$ ), the two values can be considered as equal. Although the dispersion of PdGa in our experiments is low, a molar $\mathrm{H} / \mathrm{Pd}$ ratio of 0.01 indicates that practically no hydrogen is dissolved in the bulk of the intermetallic compound and only adsorbed hydrogen (in form of $\mathrm{H}$ or hydrocarbonaceous adsorbate, see XPS part below) contributes to the signal. In contrast to the intermetallic compound, elemental palladium readily $a b$ sorbs hydrogen, forming $\beta$-palladium hydride (Figure 4) [13]. 


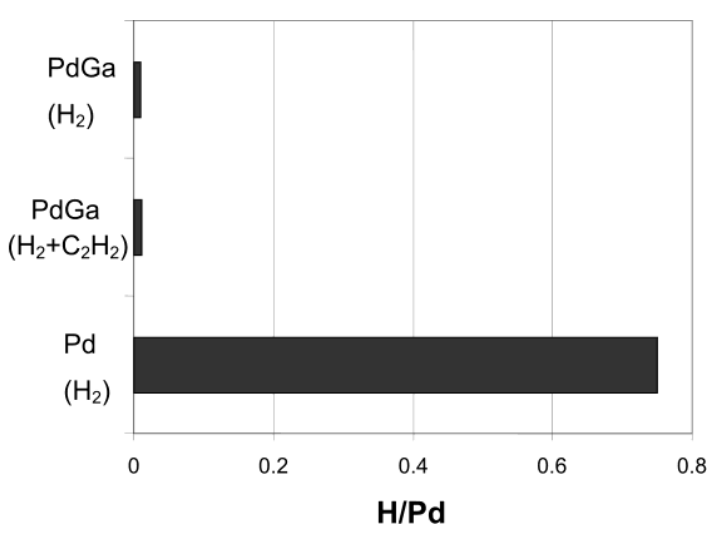

Fig. 4: Hydrogen uptake values of as-cast PdGa in comparison with pure Pd derived from PGAA experiments (see text for details).

\subsection{XPS investigations}

PdGa samples - in form of the as-cast and SPS pressed pills - were investigated before the reaction as well as in situ by synchrotron-based XPS. This technique allows monitoring of the chemical composition of the surface with high surface sensitivity and furthermore the introduction of reactive gas mixtures during surface analysis. The as-cast sample was investigated without any treatment, thus, corresponded to the sample used for catalysis. The SPS pressed samples (SPS and SPS-air) were additionally cleaned by sputtering with $\mathrm{Ar}^{+}$ions. The results obtained for different samples were carefully compared to exclude any artifacts introduced either by SPS pressing or sputtering.

Significant amounts of carbon were detected on the surfaces of all samples under UHV conditions, which is typical for active Pd catalysts investigated in this apparatus [14]. The resulting atomic ratios of $\mathrm{Pd}, \mathrm{Ga}$ and $\mathrm{C}$ are shown in Table 2. For all information depths the Pd:Ga ratio was close to the expected bulk composition of $1: 1$ within the accuracy of the method. In turn, the carbon concentration increased strongly with decreasing information depth, indicating location of carbon on top of the intermetallic surface.

Table 2: Surface atomic ratios for PdGa (SPS sample, sputtered) obtained by XPS.

\begin{tabular}{lcccc}
\hline & $\begin{array}{c}\text { KE / } \\
\mathrm{eV}\end{array}$ & $\begin{array}{c}\text { Clean PdGa } \\
\text { information } \\
\text { depth / nm }\end{array}$ & $\begin{array}{c}\mathrm{Pd}: \mathrm{Ga} \\
\pm 10 \%\end{array}$ & $\mathrm{C} /(\mathrm{Pd}+\mathrm{Ga})$ \\
\hline Before & 780 & 4.0 & $55: 45$ & 0.4 \\
reaction & 380 & 2.5 & $54: 46$ & 0.8 \\
& 150 & 1.5 & $49: 51$ & 1.9 \\
\hline \multirow{2}{*}{ During } & 780 & 4.0 & $52: 48$ & 1.7 \\
reaction & 380 & 2.5 & $56: 44$ & 2.7 \\
\hline
\end{tabular}

Investigations of the valence band region revealed a clear difference between the intermetallic compound and Pd metal (Figure 5, right). PdGa exhibits a significantly reduced electron density at the Fermi level and a shift of the Pd4d band to higher binding energy compared to elemental Pd. This is in good agreement with the bulk quantum-chemical calculations [6] which showed that the localized bonding between $\mathrm{Ga}$ and $\mathrm{Pd}$ induces the filling of the Pd $d$-band, thus shifting it away from the Fermi edge (Figure 5, left). The covalent Pd-Ga bonding interaction, resulting in a higher filling of the $\mathrm{Pd} d$-bands, prevents the formation of sub-surface hydrides - which was experimentally confirmed by PGAA - thus, diminishing the hydrogen supply for the unselective, total hydrogenation and providing high selectivity.

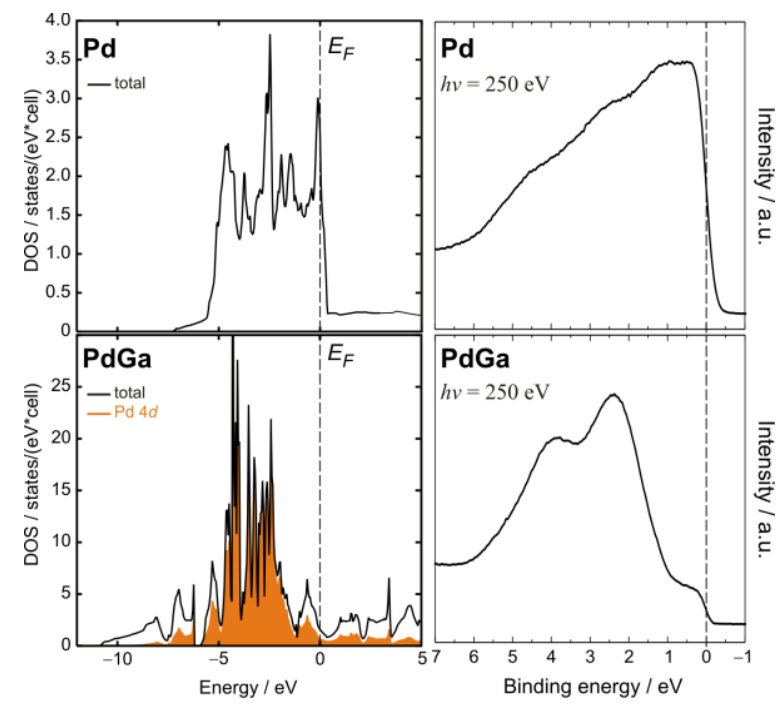

Fig. 5: Electronic density of states (left) and valence band XPS spectrum (right) of elemental Pd (top) and PdGa (bottom). Partial contributions of the Pd4d orbitals are highlighted for PdGa.

The palladium core level spectra of PdGa reveal the presence of a narrow single peak with a binding energy of $336.0 \mathrm{eV}$, which demonstrates the significant modification of the palladium electronic states in the intermetallic compound: the $\mathrm{Pd} 3 d$ peak is shifted by $1 \mathrm{eV}$ to higher binding energy compared to metallic palladium (PdGa: $336.0 \mathrm{eV}$; Pd: $335.0 \mathrm{eV}$ ) [14] (Figure 6, left). XPS depth profiling revealed no changes in the spectra except for the expected broadening with increasing wavelength of the incoming radiation, which is due to a decrease of the overall resolution. According to quantum-chemical calculations [6] and the electronegativity of the elements [15], the palladium atoms in PdGa are negatively polarized. Indeed, a higher degree of filling of the $d$-band compared to elemental Pd corresponds to a formal negatively charged palladium. Contrary to the expected negative shift, the filling of the valence $d$-band leads to a different screening of the core hole, causing the Pd3d spectra to be shifted to higher binding energy compared to elemental palladium. A similar effect was observed for other Pd-Ga intermetallic compounds, e.g. $\mathrm{Pd}_{3} \mathrm{Ga}_{7}$ and $\mathrm{Pd}_{2} \mathrm{Ga}$ [16]. A comparison 

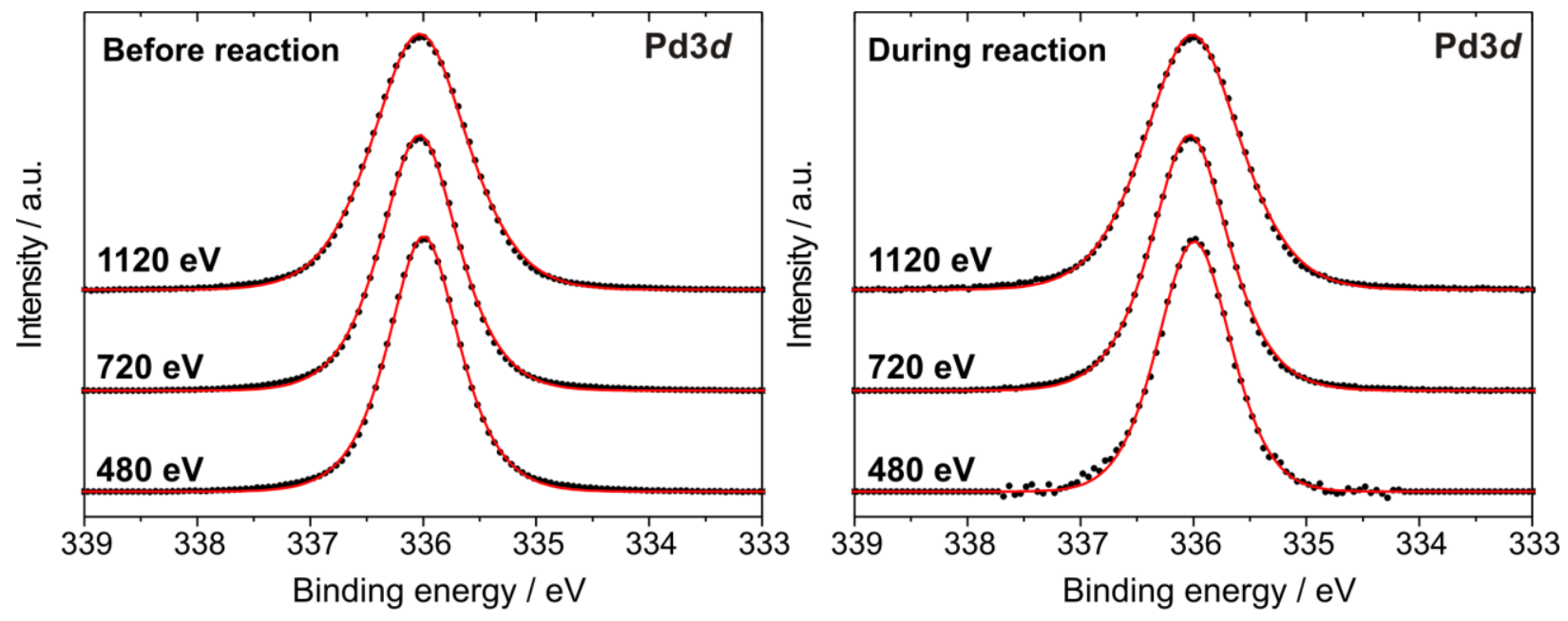

Fig. 6: Nondestructive depth profiling Pd3d XPS of PdGa (SPS sample) before (left) and during (right) the hydrogenation of acetylene.
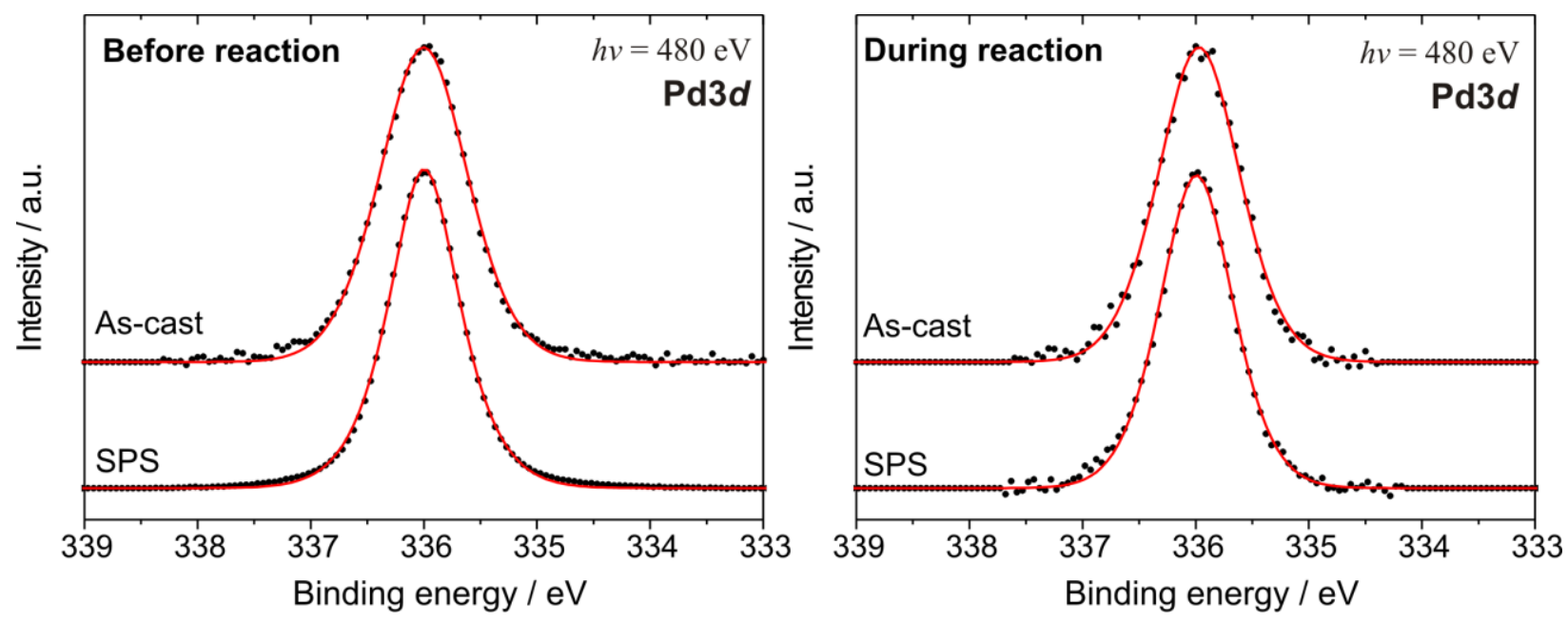

Fig. 7: Pd3 $d$ region for the as-cast and SPS-pressed PdGa before (left) and during (right) the hydrogenation of acetylene.

between the as-cast and sputtered SPS samples revealed identical Pd $3 d$ spectra (Figure 7, left). This clearly shows that the shift of the palladium core levels is an intrinsic property of PdGa and is not due to the sample treatment.

During the reaction, the outlet gas composition was monitored by mass-spectrometry which revealed that the as-cast PdGa sample was active and selective in the semihydrogenation of acetylene. The SPS pressed samples only showed negligible activity, probably due to the significantly lower surface area.

The concentration of carbon significantly increased during the in situ measurements due to the adsorption of hydrocarbons from the gas-phase, while the $\mathrm{Pd} / \mathrm{Ga}$ ratio remained unchanged (Table 2). In addition, high stability of the Pd surface state and no appearance of additional components or significant shifts of the $\operatorname{Pd} 3 d$ peak was revealed when applying reactive atmosphere and temperature (Figures 6 and 7, right). This is in contrast to metallic palladium, for which the formation of an additional $\mathrm{Pd}$ component during alkyne hydrogenation was detected [13, 17]. There, the component formed in situ was attributed to a developing carbon-containing palladium surface phase. This Pd-C phase provided the specificity of Pd to be selective in alkyne hydrogenation, by isolating the bulkdissolved hydrogen from the surface. The Pd-C surface phase exhibits a higher binding energy (335.5-335.6 eV) than elemental Pd $(335.0 \mathrm{eV})$. In the case of PdGa the valence band and, correspondingly, the $\operatorname{Pd} 3 d$ core level are already strongly modified, hence the filled Pd $d$-bands inhibit PdGa from dissolving carbon or hydrogen (XPS and PGAA). Thus, the high selectivity is an intrinsic property of the intermetallic compound PdGa.

The effect of sputtering on the PdGa surface can be clearly seen from a comparison of the $\mathrm{C} 1 s$ spectra of the ascast and SPS samples before and during the reaction (Figure 8). Before the reaction, only graphitic carbon was present in the sputtered SPS sample $(284.6 \mathrm{eV})$, while the ascast sample contained mainly aliphatic hydrocarbon species $(285.2 \mathrm{eV})[14,18]$. The spectra of both samples reveal small contributions (4-7\%) from oxygenated carbon species (containing $\mathrm{C}-\mathrm{O}$ bonds) (BE $>286 \mathrm{eV}$ ) [18]. During the reaction both samples were covered with aliphatic 

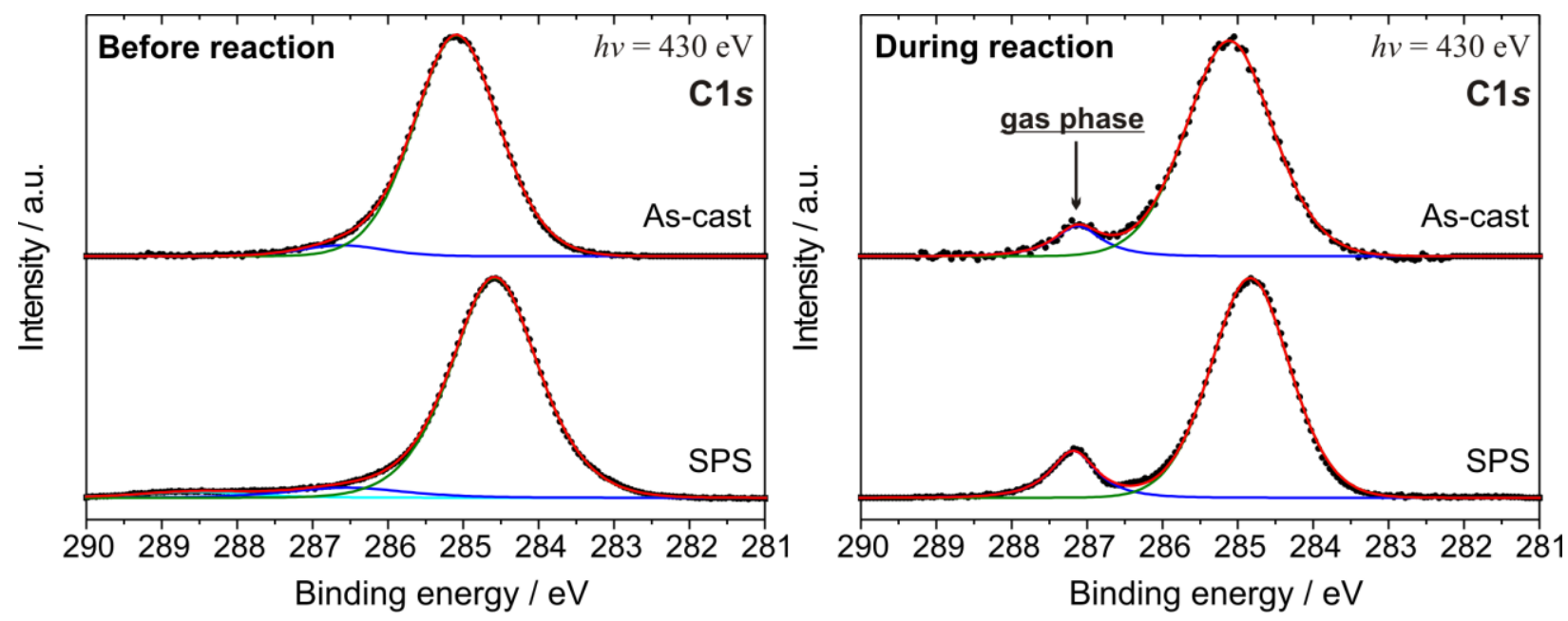

Fig. 8: $\mathrm{C} 1 s$ region for the as-cast and SPS-pressed PdGa before (left) and during (right) the hydrogenation of acetylene. The peaks are height normalized.

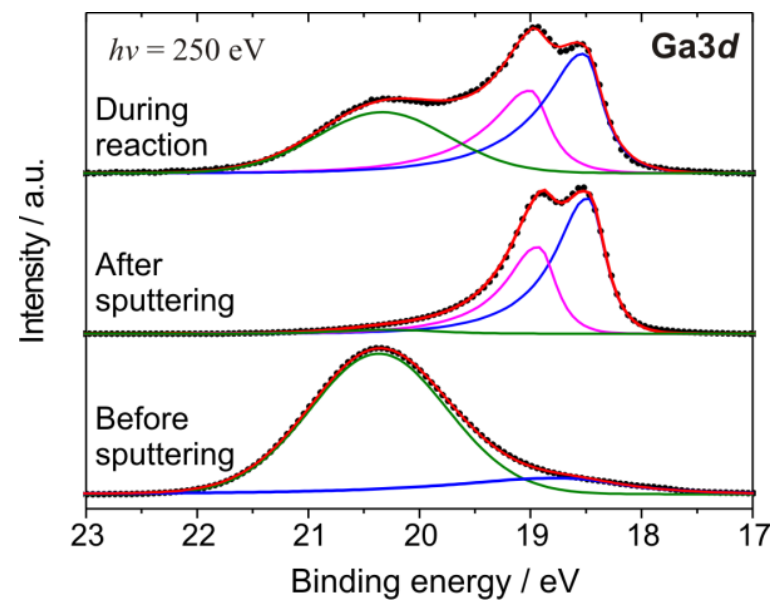

Fig. 9: Ga3d region for the PdGa (SPS-air sample) before sputtering, after sputtering and during the hydrogenation of acetylene.

hydrocarbons (284.9-285.2 eV). Besides the significant raise in carbon content (Table 2), the carbon peak position and shape for the as-cast sample remained unchanged when switching from UHV to reaction conditions (Figure 8), which shows, that during reaction the surface of the PdGa intermetallic compound is covered with aliphatic carbon species.

The Ga3d region was investigated by XPS under UHV conditions to determine gallium oxidation states as well as the presence of Ga-oxides on the surface (Figure 9). Upon contact with air, elemental gallium on the surface of PdGa can be easily oxidized and is mainly present as gallium oxide [7-8]. Two main gallium oxides are reported in the literature, $\mathrm{Ga}_{2} \mathrm{O}$ and $\mathrm{Ga}_{2} \mathrm{O}_{3}$, exhibiting $\mathrm{Ga} 3 d$ binding energies of $20.0 \mathrm{eV}$ and $21.0 \mathrm{eV}$, respectively [19-20]. In the case of the SPS-air and as-cast samples, an oxidized component with an intermediate binding energy of $20.4 \mathrm{eV}$ was detected. Additionally, a small component at lower binding energy was clearly visible, which corresponds to elemental or intermetallic gallium. After sputtering of SPSair sample, the oxide component was no longer detectable, while the intensity of the component at low binding energy increased significantly, revealing a resolvable Ga3 $d$ doublet at 18.5 and $19.0 \mathrm{eV}$ (Figure 9, middle). The binding energy of the unresolved $\mathrm{Ga} 3 d$ doublet for metallic gallium is 18.5 $\mathrm{eV}$, while for different gallium intermetallic compounds slightly higher binding energies were reported: $18.7 \mathrm{eV}$ for GaInSn [19] and 18.6 for $\mathrm{Ni}_{2} \mathrm{MnGa}$ [21]. This allows us to attribute the observed doublet to gallium in the intermetallic compound PdGa. During the reaction, the relative concentration of the gallium component at $20.4 \mathrm{eV}$ increased. The surface of the SPS-air sample - made from powder was cleaned by $\mathrm{Ar}^{+}$sputtering prior to the XPS measurements. However, grain boundaries can still contain significant amounts of oxygen, which may diffuse to the surface under reaction conditions ( $400 \mathrm{~K}, 1.1 \mathrm{mbar}$ ) and oxidize it. As was shown before, the oxide surface overlayer is quite stable and can not be reduced even under more severe reduction conditions (500 mbar of hydrogen at $573 \mathrm{~K}$ [7]).

\section{4. FTIR}

For a direct comparison, $\mathrm{CO}$ adsorption experiments were performed on both $\mathrm{PdGa}$ and the $\mathrm{Pd} / \mathrm{Al}_{2} \mathrm{O}_{3}$ reference catalyst, and the obtained spectra of the latter are shown in Figure 10. $\mathrm{CO}$ adsorption at $77 \mathrm{~K}$ resulted in adsorption maxima at $2182 \mathrm{~cm}^{-1}, 2155 \mathrm{~cm}^{-1}, 2130 \mathrm{~cm}^{-1}, 2107 \mathrm{~cm}^{-1}$, $2076 \mathrm{~cm}^{-1}$ and $1994 \mathrm{~cm}^{-1}$ (Figure 10, spectrum a). The intensity of the bands at $2182 \mathrm{~cm}^{-1}$ and $2155 \mathrm{~cm}^{-1}$ decreased rapidly upon evacuation (spectra $b$ - $f$ ), indicating that they are due to weakly adsorbed surface species. According to the literature, these two bands arise from $\mathrm{CO}$ species adsorbed on alumina and can be assigned to $\mathrm{Al}^{\delta+}$ $\mathrm{CO}$ and $\mathrm{OH}-\mathrm{CO}$, respectively [22]. The other set of signals in the region of $2130-1885 \mathrm{~cm}^{-1}$ exhibited a higher 


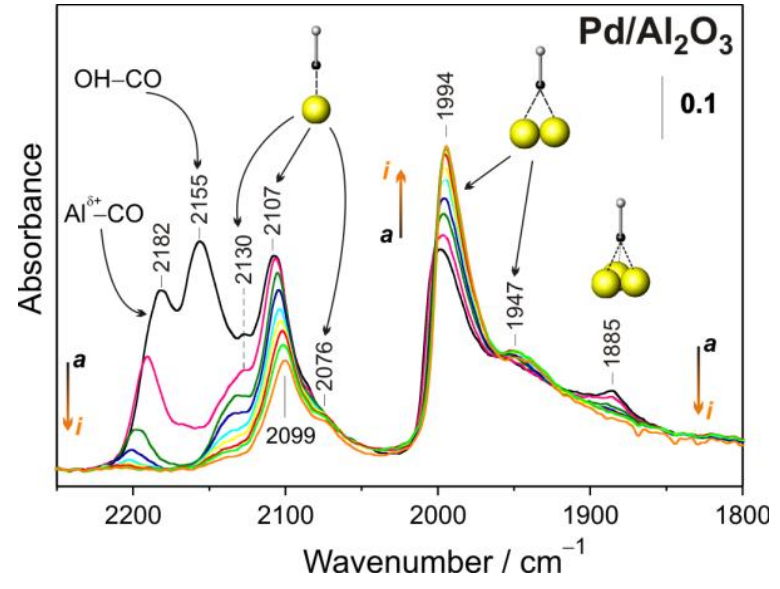

Fig. 10: FTIR spectra of $\mathrm{CO}(1 \mathrm{mbar})$ adsorbed at $77 \mathrm{~K}$ on $\mathrm{Pd} / \mathrm{Al}_{2} \mathrm{O}_{3}(a)$; during evacuation at the same temperature $(b-f)$; upon increasing of the temperature to $106 \mathrm{~K}(\mathrm{~g}), 110 \mathrm{~K}(\mathrm{~h})$ and 124 $\mathrm{K}(i)$.

stability. While the intensities of the bands at 2130-2076 $\mathrm{cm}^{-1}$ and the weak band at $1885 \mathrm{~cm}^{-1}$ were slowly decreasing with decreasing CO coverage, the bands at $1994 \mathrm{~cm}^{-1}$ and $1947 \mathrm{~cm}^{-1}$ gained intensity. According to numerous investigations of $\mathrm{CO}$ adsorption on various $\mathrm{Pd}$ surfaces in the literature [23-29] the bands can be assigned as follows: bands in the region $2130-2070 \mathrm{~cm}^{-1}$ correspond to linearly bound CO, bands in the region $2000-1930 \mathrm{~cm}^{-1}$ represent bridged $\mathrm{CO}\left(\mathrm{Pd}_{2}-\mathrm{CO}\right)$ and the bands in the region 1900 $1850 \mathrm{~cm}^{-1}$ are assigned to $\mathrm{CO}$ molecules bound to three palladium atoms $\left(\mathrm{Pd}_{3}-\mathrm{CO}\right)$. The recorded spectra are in good agreement with typical spectra of $\mathrm{Pd} / \mathrm{Al}_{2} \mathrm{O}_{3}$ catalysts with high Pd loading [29]. The dipole-dipole coupling of neighboring $\mathrm{CO}$ molecules had a strong impact on the position of the bands, resulting in a pronounced $\mathrm{CO}$ coverage dependence [23]. For example, the band at $2107 \mathrm{~cm}^{-1}$ shifted to $2099 \mathrm{~cm}^{-1}$ with changing CO coverage. Summarizing the obtained results and the literature data, two spectroscopic criteria can be identified to distinguish between isolated and agglomerated palladium sites: (i) the presence of bands in the spectra due to bridged $\mathrm{CO}$ or $\mathrm{CO}$ bound to three palladium atoms and (ii) the coverage dependence of the band positions.

From the crystal structure of PdGa, the complete isolation of Pd atoms on the surface is expected. The palladium atoms are surrounded by seven gallium atoms at distances ranging from 2.54 to $2.70 \AA$ (Figure 11C) and the closest Pd-Pd distance in PdGa is $3.0 \AA$, which is $10 \%$ longer than for elemental palladium. Such an isolation of the adsorption centers can lead to a significant red shift of the CO vibrational frequency [23-28]. Up to now, the isolation has either been achieved by decreasing the $\mathrm{CO}$ partial pressure [23-27] or by alloying Pd with another metal, e.g. $\mathrm{Ag}$ [28]. In the first case, the full isolation of the Pd-CO was not achieved because at low $\mathrm{CO}$ partial pressures the bridged $\mathrm{Pd}_{2}-\mathrm{CO}$ species becomes energetically more favorable. However, a significant red shift of $\sim 30 \mathrm{~cm}^{-1}$ was detected for single crystals and nanoparticulate Pd samples
[23-27]. Isolating the $\mathrm{Pd}$ atoms by alloying $\mathrm{Pd}$ with $\mathrm{Ag}$ leads to the formation of a disordered Pd-Ag alloy and causes a red shift of the on-top Pd-CO band from $2078 \mathrm{~cm}^{-}$ ${ }^{1}$ for $\mathrm{Pd} / \mathrm{SiO}_{2}$ to $2048 \mathrm{~cm}^{-1}$ and $2034 \mathrm{~cm}^{-1}$ for different Pd$\mathrm{Ag} / \mathrm{SiO}_{2}$ samples depending on the Pd:Ag ratio. Additionally, the intensity of the band corresponding to adsorbed bridged $\mathrm{CO}$ decreases with increasing silver content. However, the presence of a band corresponding to bridged $\mathrm{CO}$, even for a low Pd:Ag ratio (1:4), demonstrates that in the disordered Pd-Ag alloys full isolation of the Pd atoms can not be achieved due to the statistical distribution of $\mathrm{Pd}$ and $\mathrm{Ag}$ atoms on the crystallographic positions and to segregation phenomena [28].

Adsorption of $\mathrm{CO}$ on $\mathrm{PdGa}$ at room temperature resulted in the appearance of only one sharp band with a maximum at $2047 \mathrm{~cm}^{-1}$ and no coverage dependent frequency shift was observed during evacuation (Figure 11A, spectra $a-c$ ). Because of the low stability and the position at $2047 \mathrm{~cm}^{-1}$, the observed band is assigned to $\mathrm{CO}$ adsorbed on Pd in on-top position. The significant red-shift of the band is a result of the strong electronic modification as detected by XPS measurements and quantum chemical calculations, and corresponds to a formally negatively charged palladium, $\mathrm{Pd}^{\delta-}$. Due to the isolation of the $\mathrm{Pd}$ atoms in $\mathrm{PdGa}$, no characteristic bands for bridged $\mathrm{CO}$ or triple-bound $\mathrm{CO}$ were detected in the region from 2000$1850 \mathrm{~cm}^{-1}$. In combination with the absence of dipoledipole coupling this is a clear indication that the $\mathrm{Pd}$ atoms on the surface of PdGa are indeed isolated as expected from the bulk crystal structure.

Variation of the CO coverage by decreasing the temperature of the FT-IR experiments caused no band shift - as expected for $\mathrm{CO}$ adsorbed on isolated $\mathrm{Pd}$ atoms (Figure $11 \mathrm{~A}$, spectra $\mathrm{c}-\mathrm{h}$ ). Low temperature experiments revealed a fine structure of the absorption band (Figure 11B), consisting of three bands at $2030 \mathrm{~cm}^{-1}, 2044 \mathrm{~cm}^{-1}$ and $2053 \mathrm{~cm}^{-1}$. These bands are still in the characteristic range for on-top adsorbed $\mathrm{CO}$ on isolated Pd atoms [27-28], but they indicate some heterogeneity of the surface. While the palladium atoms are still isolated one from another, at least three different types of palladium atoms are present on the surface of PdGa. Small variations of 10 to $20 \mathrm{~cm}^{-1}$ have been observed and calculated for the adsorption of $\mathrm{CO}$ on top of Pd with different surroundings, e.g. Pd atoms being part of a face, an edge or a corner of a Pd nanoparticle [25]. Since the particles in this study are much larger it is not very likely that the concentration of edge and corner $\mathrm{Pd}$ atoms is high enough to explain the three signals with similar intensity. It has been reported for $\operatorname{Pd}(111)$ and $\operatorname{Pd}(100)$, that the vibrational frequency of bridged $\mathrm{CO}$ depends on the crystallographic surface on which the $\mathrm{CO}$ is adsorbed [30]. The variations are in the region of $20-30 \mathrm{~cm}^{-1}$ and so the fine structure of the absorption band in the case of PdGa may arise from $\mathrm{CO}$ adsorbed on different crystallographic surfaces. The splitting also might be connected to the presence of the Ga-oxides which are partially covering the surface as revealed by the XPS measurements. IR investigations on PdGa single crystal surfaces may help to clarify this issue. 


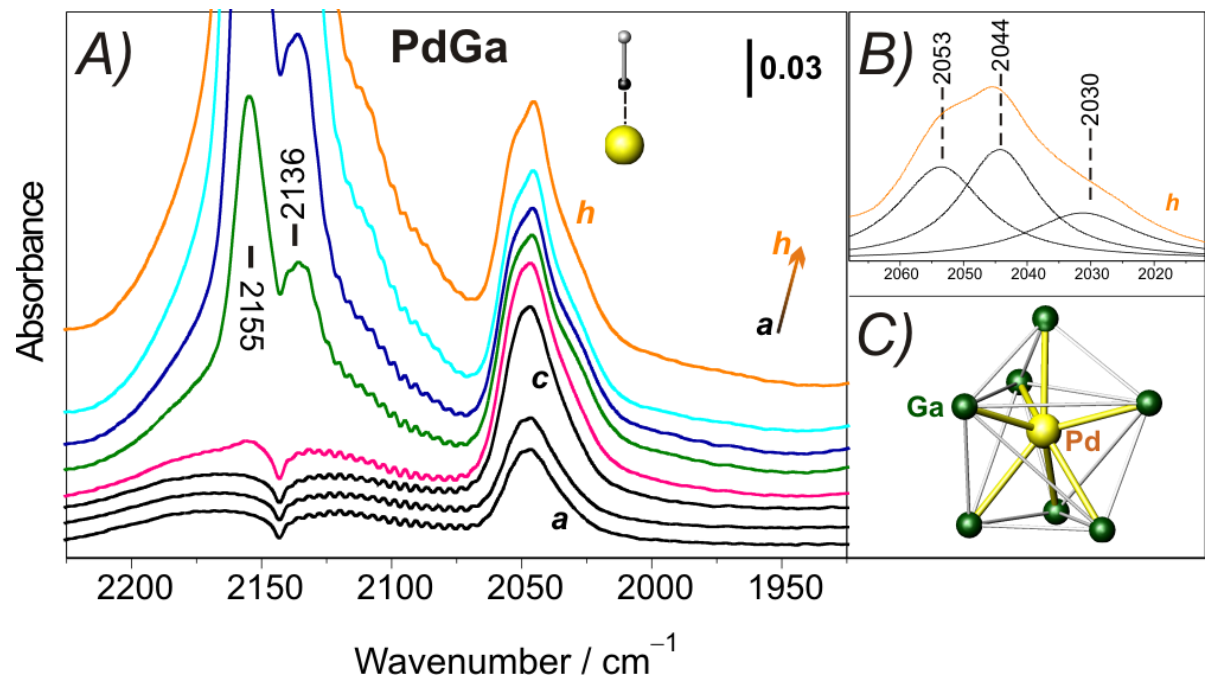

Fig. 11: A) FTIR spectra of CO (50 mbar) adsorbed at room temperature on PdGa (spectrum $a$ ); during evacuation at the same temperature (spectra $b$-c); during subsequent reduction of the temperature to $201 \mathrm{~K}$ (spectrum $d$ ), $181 \mathrm{~K}$ (spectrum $e$ ), $159 \mathrm{~K}$ (spectrum $f$ ), $140 \mathrm{~K}$ (spectrum $g$ ) and $130 \mathrm{~K}$ (spectrum $h$ ). Bands at $2155 \mathrm{~cm}^{-1}$ and $2136 \mathrm{~cm}^{-1}$ correspond to $\mathrm{CO}$ adsorbed on the hydroxyl groups of the silica. B) Deconvolution of the spectrum $h$ recorded at $130 \mathrm{~K}$. C) Coordination of the Pd atoms in the crystal structure of bulk PdGa by seven Ga atoms.

To summarize, our detailed surface characterization shows the high potential of intermetallic compounds as selective hydrogenation catalysts. PdGa was selected based on the knowledge of its crystal and electronic structures. It. was shown by in situ XRD and in situ EXAFS that the bulk structure of PdGa is stable during the semi-hydrogenation of acetylene [6-7]. This investigation confirmed that the combination of a well-ordered crystal structure and the covalent bonding between palladium and gallium allows the drop of the main drawbacks of Pd-based catalysts - low selectivity and long-term instability. XPS measurements revealed the electronic structure of the surface of PdGa being close to the electronic structure of the bulk, and FTIR spectra of adsorbed CO confirmed the complete isolation of the surface palladium atoms. Both XPS and FTIR showed a strong modification of the Pd $d$-band resulting in changed adsorption properties. In situ XPS revealed perfect stability of the surface excluding segregation and sub-surface chemistry, like the incorporation of $\mathrm{C}$ and/or $\mathrm{H}$ atoms. In situ PGAA confirmed the absence of bulk dissolved hydrogen in PdGa. Additionally, our study showed that gallium on the surface of PdGa is easily oxidized, even upon contact with air at room temperature. However, this process did not involve palladium, as was shown by XPS on as-cast and sputtered PdGa. The presence of gallium oxides may play a role in hydrogen spillover, as it was shown for the $\mathrm{Ga}_{2} \mathrm{O}_{3}-$ $\mathrm{Pd} / \mathrm{SiO}_{2}$ system [31]. The superior catalytic properties of $\mathrm{PdGa}$ can be assigned to a) the elimination of sub-surface hydrogen, thus, increasing the selectivity, b) the isolation of $\mathrm{Pd}$ atoms on the surface of PdGa, which restricts the possible adsorption configurations of the acetylene molecules on the surface, and c) the modification of adsorption and desorption properties due to changes in the electronic states compared to elemental palladium.

\section{Conclusions}

A highly selective hydrogenation catalyst - the intermetallic compound PdGa - was studied by FTIR, in situ XPS, in situ PGAA as well as SEM. The isolation of Pd atoms on the surface of PdGa - as expected from the bulk crystal structure - was confirmed by FTIR of adsorbed CO. In addition, a strong modification of the $\mathrm{Pd} d$-states due to covalent bonding between palladium and gallium was detected by XPS. High stability of the surface was revealed by in situ investigations: segregation of Pd and dissolution of $\mathrm{C}$ and/or $\mathrm{H}$ atoms could be excluded based on XPS and PGAA measurements. The observed properties form the basis for the high selectivity and long-term stability of $\mathrm{PdGa}$ in the semi-hydrogenation of acetylene. We have demonstrated that active-site isolation concept can be successfully realized exploring intermetallic compounds, which allows a rational control over surface properties of the catalyst. Our results uncover high potential of intermetallic compounds in heterogeneous catalysis.

\section{Acknowledgement}

The authors express their gratitude to P. Scheppan, Dr. U. Burkhardt and G. Weinberg for the SEM investigations and Dr. G. Auffermann for chemical analysis. We thank BESSY and the Budapest Neutron Centre for providing beamtimes and continuing support during the XPS and PGAA experiments. 


\section{References}

[1] A.N.R. Bos, K.R. Westerterp, Chem. Eng. Process. 32 (1993), 1; A. Borodzinski, G.C. Bond, Catal. Rev. 48 (2006) 91; H. Arnold, F. Döbert, J. Gaube, in Handbook of Heterogeneous Catalysis, Eds. G. Ertl, H. Knözinger, J. Weitkamp (VCH, Weinheim, 1997) p. 2165.

[2] A. Molnár, A. Sárkány, M. Varga, J. Mol. Catal. A 173 (2001) 185; P. Albers, J. Pietsch, S.F. Parker, J. Mol. Catal. A 173 (2001) 275; A. Sárkány, A.H. Weiss, L. Guczi, J. Catal. 98 (1986) 550

[3] E.G. Derouane, J. Mol. Catal. 25 (1984) 51; L. Guczi, Catal. Today 101 (2005) 53; N.A. Khan, S. Shaikhutdinov, H.J. Freund, Catal. Lett. 108 (2006) 159; N.A. Khan, A. Uhl, S. Shaikhutdinov, H. J. Freund, Surf. Sci. 600 (2006) 1849; D. Mei, P.A. Sheth, M. Neurock, C.M. Smith, J. Catal. 242 (2006) 1 .

[4] G.C. Bond, P.B. Wells, J. Catal. 5 (1966) 65; C.M. Pradier, M. Mazina, Y. Berthier, J. Oudar, J. Mol. Catal. 89 (1994) 211; G. Rupprechter, G.A. Somorjai, Catal. Lett. 48 (1997) 17; B. Coq, F. Figueras, J. Mol. Catal. A 173 (2001) 117; A.M. Doyle, S.K. Shaikhutdinov, S.D. Jackson, H.J. Freund, Angew. Chem. Int. Ed. 42 (2003) 5240; G. Rupprechter, M. Morkel, H.J. Freund, R. Hirschl, Surf. Sci. 554 (2004) 43; M. Morkel, G. Rupprechter, H.J. Freund, Surf. Sci. 588 (2005) L209-L219.

[5] M.M. Johnson, D.W. Walker, G.P. Nowak, US 4404124, Phillips Petroleum Company, 1983; V.M. Trontl, I. Pletikosic, M. Milun, P. Pervan, P. Lazic, D. Sokcevic, R. Brako, Phys. Rev. B 72 (2005) 235418.

[6] K. Kovnir, M. Armbrüster, D. Teschner, T.V. Venkov, F.C. Jentoft, A. Knop-Gericke, Yu. Grin, R. Schlögl, Sci. Technol. Adv. Mater. 8 (2007) 420; K. Kovnir, M. Armbrüster, J. Osswald, T. Ressler, R.E. Jentoft, R. Giedigkeit, Yu. Grin, R. Schlögl, Angew. Chem. Int. Ed. (2008) submitted.

[7] J. Osswald, R. Giedigkeit, R.E. Jentoft, M. Armbrüster, F. Girgsdies, K. Kovnir, T. Ressler, Yu. Grin, R. Schlögl, J. Catal. (2008) submitted; J. Osswald, K. Kovnir, M. Armbrüster, R. Giedigkeit, R.E. Jentoft, U. Wild, Yu. Grin, R. Schlögl, J. Catal. (2008) submitted.

[8] K. Kovnir, J. Osswald, M. Armbrüster, R. Giedigkeit, T. Ressler, Yu. Grin, R. Schlögl, Stud. Surf. Science Catal. 162 (2006) 481

[9] H. Bluhm, M. Hävecker, A. Knop-Gericke, E. Kleimenov, R. Schlögl, D. Teschner, V.I. Bukhtiyarov, D.F. Ogletree, M. Salmeron, J. Phys. Chem. B 108 (2004) 14340.

[10] T.-Y. Um, T. Abe, S. Sumi, J. Mater. Synth. Process. 7 (1999) 303; C. Recknagel, N. Reinfried, P. Höhn, W. Schnelle, H. Rosner, Yu. Grin, A. Leithe-Jasper, Sci. Technol. Adv. Mater. 8 (2007) 357.

[11] NIST Electron Inelastic Mean Free Path Database, version 1.1, http://www.nist.gov/srd/nist71.htm.

[12] Zs. Révay, T. Belgya, Zs. Kasztovszky, J.L. Weil, G.L. Molnár, Nucl. Instr. Meth. B 213 (2004) 385; G.L. Molnár, Handbook of Prompt Gamma Activation Analysis with Neu- tron Beams, (Kluwer Academic Publishers, Dordrecht/London/Boston, 2004).

[13] D. Teschner, J. Borsodi, A. Wootsch, Zs. Révay, M. Hävecker, A. Knop-Gericke, S.D. Jackson, R. Schlögl, Science 320 (2008) 86.

[14] D. Teschner, A. Pestryakov, E. Kleimenov, M. Hävecker, H. Bluhm, H. Sauer, A. Knop-Gericke, R. Schlögl, J. Catal. 230 (2005) 186; D. Teschner, A. Pestryakov, E. Kleimenov, M. Hävecker, H. Bluhm, H. Sauer, A. Knop-Gericke, R. Schlögl, J. Catal. 230 (2005) 230, 195.

[15] R.T. Sanderson, Chemical bonds and bond energy, 2nd ed. (Academic Press, New York, 1976).

[16] K. Kovnir, D. Teschner, M. Armbrüster, P. Schnörch, M. Hävecker, A. Knop-Gericke, Yu. Grin, R. Schlögl, BESSY Highlights 2007, 22.

[17] D. Teschner, E. Vass, M. Hävecker, S. Zafeiratos, P. Schnörch, H. Sauer, A. Knop-Gericke, R. Schlögl, M. Chamam, A. Wootsch, A.S. Canning, J.J. Gamman, S.D. Jackson, J. McGregor, L.F. Gladden. J. Catal. 242 (2006) 26.

[18] N.M. Rodriguez, P.E. Anderson, A. Wootsch, U. Wild, R. Schlögl, Z. Paál. J. Catal. 197 (2001) 365; Z. Paál, U. Wild, R. Schlögl, Phys. Chem. Chem. Phys. 3 (2001) 4644.

[19] F. Scharmann, G. Cherkashinin, V. Breternitz, Ch. Knedlik, G. Hartung, Th. Weber, J.A. Schaefer, Surf. Interface Anal. 36 (2004) 981.

[20] R. Carli, C.L. Bianchi, Appl. Surf. Sci. 74 (1994) 99 ; C.C. Surdu-Bob, S.O. Saied, J.L. Sullivan, Appl. Surf. Sci. 183 (2001) 126.

[21] C. Biswas, S.R. Barman, Appl. Surf. Sci. 252 (2006) 3380

[22] C. Morterra, G. Magnacca, Catal. Today 27 (1996) 497.

[23] K. Wolter, O. Seiferth, H. Kuhlenbeck, M. Bäumer, H.-J. Freund, Surf. Sci. 399 (1998) 190; K. Wolter, O. Seiferth, J. Libuda, H. Kuhlenbeck, M. Bäumer, H.-J. Freund, Surf. Sci. 402-404 (1998) 428.

[24] H. Unterhalt, G. Rupprechter, H.-J. Freund, J. Phys. Chem. B 106 (2002) 356.

[25] I.V. Yudanov, R. Sahnoun, K.M. Neyman, N. Rösch, J. Hoffmann, S. Schauermann, V. Johánek, H. Unterhalt, G. Rupprechter, J. Libuda, H.-J. Freund, J. Phys. Chem. B 107 (2003) 255.

[26] S. Bertarione, D. Scarano, A. Zecchina, V. Johánek, J. Hoffmann, S. Schauermann, M.M. Frank, J. Libuda, G. Rupprechter, H.-J. Freund, J. Phys. Chem. B 108 (2004) 108, 3603.

[27] P. Gelin, A.R. Sedle, J.T. Yates, J. Phys. Chem. 88 (1984) 2978.

[28] M. Li, J. Shen, Mater. Chem. Phys. 68 (2001) 204

[29] M. Skotak, Z. Karpiński, W. Juszczyk, J. Pielaszeka, L. Kępiński, D.V. Kazachkin, V.I. Kovalchuk, J.L. d'Itri, J. Catal. 227 (2004) 11.

[30] J. Szanyi W.K. Kuhn, D.W. Goodman, J. Vac. Sci. Techn. A 11 (1993) 1969.

[31] S.E. Collins, D.L. Chiavassa, A. L. Bonivardi, M.A. Baltanás, Catal. Lett. 103 (2005) 83. 